Original Research

\title{
Soil Water Characteristic Curve Test of Waste under Different Compaction Densities and Analysis of the Multi-Factors that Affect the Instability of Landfill Slopes
}

\author{
Meirong Dang, Junrui Chai*, Zengguang Xu**, Yuan Qin \\ State Key Laboratory of Eco-hydraulics in Northwest Arid Region, Xi' an University of Technology, \\ Xi'an, Shaanxi 710048, China
}

Received: 13 April 2021

Accepted: 27 September 2021

\begin{abstract}
The soil water characteristic curves (SWCC) of municipal solid waste (MSW) samples with different compaction densities from the Jiangcungou landfill in Xi'an are tested in a laboratory. In addition, the Jiangcungou landfill was used to analyze the effect of different slope ratios, rainfall amounts and patterns, compaction degrees, and the leachate drainage system on stability of the landfill based on the saturated-unsaturated seepage theory and the Morgenstern-Price method. The results are summarized as follows. First, the SWCC of MSW samples with different compaction densities and the same components gradually converged with an increase in matric suction, and it nearly converged to one point when the matric suction was approximately $10^{4} \mathrm{kPa}$. The volumetric water content of the converge point was the greatest in the deep layer, followed by the middle and shallow layers. Second, for the MSW samples with the same compositions, in the range of dry densities tested, MSW samples with a large compaction density tended to have a small $\alpha$, a saturated water content of $\theta_{s}$ and $n_{v}$, and little differences in the residual water content, $\theta_{r}$. Third, for the compaction, drainage system, slope, and rainfall, the value of $\mathrm{R}$ (i.e., range) was $0.49,0.22,0.19$, and 0.12 , respectively, in the orthogonal test. Thus, the order of impact on the landfill is as follows: the compaction, drainage system, slope, and rainfall intensity.
\end{abstract}

Keywords: landfill slope, soil water characteristic curve, drainage system, compaction, seepage

*e-mail: jrchai@xaut.edu.cn

**e-mail: xuzengguang@xaut.edu.cn 


\section{Introduction}

Landfills are one of the most widely used municipal solid waste (MSW) disposal methods worldwide, especially in developing countries, such as India and China. According to statistics, at least $91 \%$ of MSW was disposed of in landfills in India and China [1]. In addition, landfilling is a predominant method and unavoidable step in MSW management in China [2]. However, the instability of landfills still occur frequently around the world [3]. Tables 1 and 2 summarize information regarding the instability of several sanitary landfills and uncontrolled landfills around the world. It is easy to see that landfill instability can not only cause great damage to people's lives and property, but can cause serious environmental pollution as well. Thus, it is important to focus on the factors that affect the instability of landfill slopes.

Landfill instability has attracted international attention from scientists and engineers. Several researchers have discussed the influence of factors on the stability of the landfill slope based on the tests or the finite element calculation. Yu and Batlle (2011) conducted quasi-three-dimensional slope stability analysis in a municipal solid waste landfill and analyzed impacts of waste parameters including shear strength and unit weight, leachate level, and time on safety [14]. Qiu et al. (2012) studied the effects of rainfall patterns of decreasing, central, enhanced, and average types on landfill stability based on the Suzhou Qizishan Landfill in Suzhou, China [15]. Hossain and Haque (2009) discussed the instabilities of MSW landfills with decomposition and found that the factor of safety decreased as MSW degraded with time [12]. Chen et al. (2017) investigated the landfill failure induced by rising water levels in a laboratory and analyzed the failure mechanism of landfills [16]. Koerner and Soong (2000b) discussed the impact of different leachate distribution scenarios on landfill stability [17]. In summary, the most recent studies have tended to pay more attention to the influence of a single factor on landfill stability.

However, a landfill failure is not often caused by a single factor. Tables 1 and 2 summarize the instability information of 14 landfills, nine of which were caused by the combination of two or more factors. For example, the failure at the Shenzhen Xiaping landfill in 2008 was caused by the combination of heavy rainfall and a failed leachate drainage system [7]. Xerolakka Landfill in Greece failed in 2010 because of rainfall, a steep slope, inadequate compaction, and no daily soil cover [6]. The failure at the Xi'an Jiangcungou landfill in 2014 was caused by the combination of rainfall and mechanical dynamic load [5]. The 1997 failure of the Dona Juana landfill in Colombia was caused by a combination of leachate recirculation and inconsistent compaction [8]. Therefore, it is necessary to study the stability of a landfill under a combination of factors.

In summary, there are many factors that can influence the stability of a landfill slope. Among these,

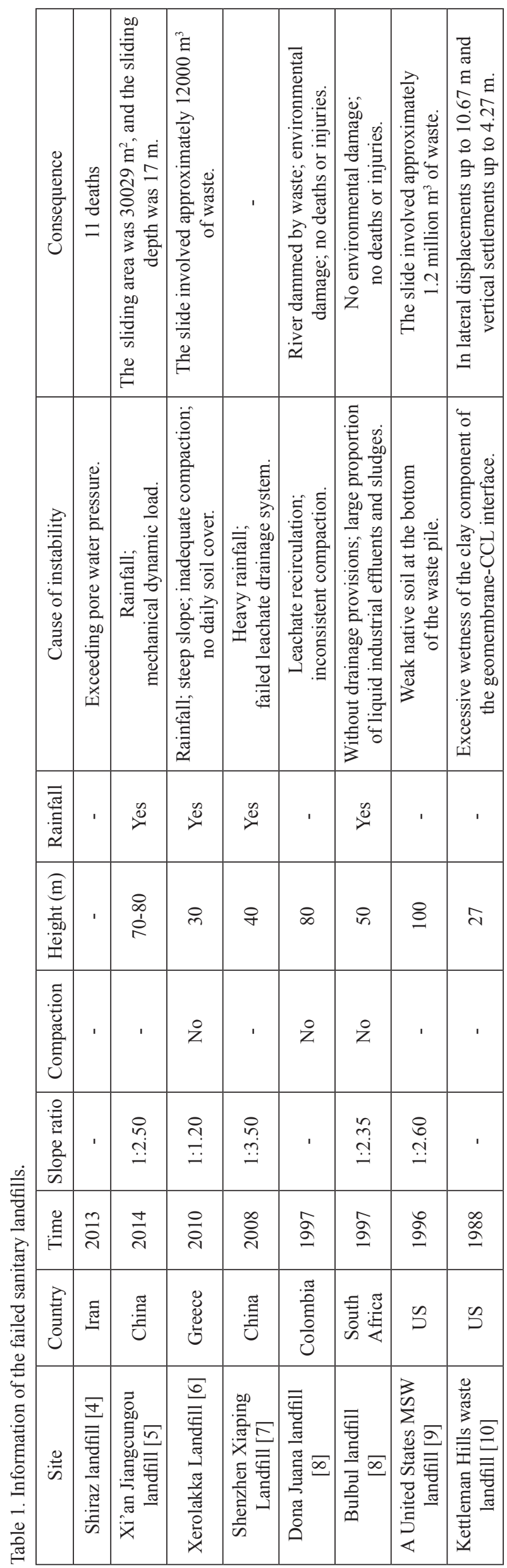




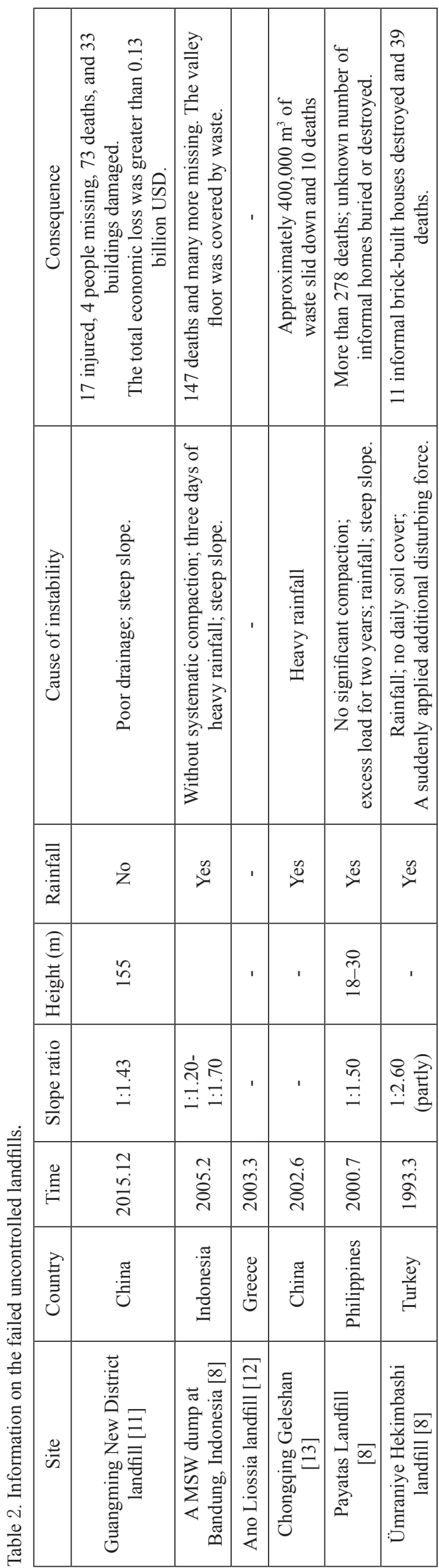

rainfall, steep slope, inadequate compaction, and failed leachate drainage systems are common ones according to the summary of the failure causes in Tables 1 and 2. From the numerical simulation point of view, if all possible combinations of the factors and levels are calculated, that is a full-scale simulation. However, a full-scale numerical simulation is time-consuming for a number of reasons. The orthogonal array design involves the selection of some representative combinations of factors and levels for the experiments. As the construction principles of the orthogonal table involve balanced dispersion and neat comparability, the number of experiments designed via this method is small, and the method can reflect objective laws; thus, it has a high calculation efficiency [18]. In addition, it has been proven that this method can obtain the optimal conditions of each parameter in a limited number of experimental trials [19].

The soil water characteristic curve (SWCC) represents the relationship between the volumetric water content and the matric suction of soil. It can be used to predict the unsaturated permeability of a porous medium indirectly [20] and is required for the saturated-unsaturated seepage calculation. Currently, researchers are paying more attention to the effect of age of MSW on SWCC [21, 22]. However, the effect of the compaction degree of the MSW on the SWCC has only been reported in a few articles. Therefore, it is necessary to explore the effect of the compaction degree on the SWCC.

In this study, SWCC of the MSW from Jiangcungou landfill in shallow, middle and deep layer under different compaction degrees was tested with the H-1400PF SWCC measurement system in the laboratory. We discussed different combinations of the four main factors (i.e., rainfall, slope ratio, compaction degree, and leachate drainage system) on landfill stability, and the saturated-unsaturated seepage calculations and stability calculations were conducted for each working condition. The sensitivity analysis of the influence of each factor on the safety factor was conducted using an orthogonal experiment. The importance of these factors for the landfill slope was assessed from a quantitative perspective to provide a reference for the operation and management of landfills.

\section{Numerical Method}

The mathematical model for the saturatedunsaturated seepage analysis is shown in Eq. (1):

$$
\frac{\partial}{\partial x}\left(k \frac{\partial H}{\partial x}\right)+\frac{\partial}{\partial y}\left(k \frac{\partial H}{\partial y}\right)+Q=\frac{\partial \theta}{\partial t}
$$

where $H, k, Q, \theta$, and $t$ are the total head, the hydraulic conductivity, the boundary flow from outside, the volumetric water content, and time, respectively. 
The volumetric water content and the hydraulic conductivity were fitted based on Eqs. (2) and (3) [23]:

$$
\theta=\theta_{r}+\frac{\theta_{s}-\theta_{r}}{\left[1+(\alpha \psi)^{n_{v}}\right]^{m}}
$$

where $\theta_{s}$ and $\theta_{r}$ are the saturated and residual volumetric water contents, respectively, and $\psi$ is the matric suction in $\mathrm{kPa}$. In addition, $\alpha, m$, and $n_{v}$ are the curve fitting parameters, with $m$ assumed to be equal to1-1/n :

$$
k=k_{s} \frac{\left\{1-(\alpha \psi)^{n_{v}-1}\left[1+(\alpha \psi)^{n_{v}}\right]^{-m}\right\}^{2}}{\left[1+(\alpha \psi)^{n_{v}}\right]^{\frac{m}{2}}}
$$

where $k$ is the hydraulic conductivity and $k_{s}$ is the saturated hydraulic conductivity. The meaning and value of the remaining parameters are the same as those in Eq. (2).

The common methods for determining the safety factor includes the general limit balance method, the Fellenius method, the Bishop method, the simplified Janbu method, the Spencer method, the MorgensternPrice method, and various others. Compared with other methods, the Morgenstern-Price method has the advantages that it considers the shear force and normal force between the strips. It also satisfies the balance of the moment balance and force. Therefore, the Morgenstern-Price method was utilized in this study.

\section{Test and Parameters}

\section{The SWCC Test}

The SWCC is an important parameter for saturated and unsaturated seepage analysis. MSW samples were collected from Jiangcungou landfill located in Xi'an of the Shannxi Province in China; this landfill is the only waste disposal location near the urban area of Xi'an. Waste samples with landfill ages of 3 years, 6 years, and 10 years were collected from the Jiangcungou landfill site and their detailed compositions can be found in Dang et al. (2020) [22]. The waste samples with landfill ages of 3 years, 6 years, and 10 years represented landfilled MSW in the shallow, middle, and deep layers, respectively. The humus soil and plastic are from landfill, and the composition of paper, wood, small gravel, glass, and textiles are replaced by waste paper, wood chips, crushed stone, glass bottles, and old clothes from daily life in this manuscript. The waste with big particle was shredded into small pieces $(5-\mathrm{mm}$ maximum particle size). The shredded samples were blended according to the detailed compositions, and the sample preparation was based on the specification [24]. Certain weights of the samples were compacted in a cutting ring with the volume of $100 \mathrm{~cm}^{3}$. Filter paper and permeable stone were placed on the upper and lower parts of the ring knife, respectively. After it was fixed with rubber bands, the waste sample was saturated in a vacuum saturation cylinder for test.

The H-1400PF SWCC measurement system in Fig. 1 was used to measure SWCC of MSW. The principle is to convert the potential energy of the centrifugal force field into the matric potential of the gravitational field at a certain speed, as shown in Eq. (4).

$$
\rho g H=\rho h \omega^{2}\left(r-\frac{h}{2}\right)
$$

where $\rho$ is the density of water; $H$ is the capillary pressure head, $\mathrm{cm} ; g$ is the gravity acceleration of $980 \mathrm{~cm} / \mathrm{s}^{2} ; \omega$ is angular velocity, $\omega=2 \pi N / 60, \mathrm{rad} / \mathrm{s} ; N$ is the rotational speed, $\mathrm{rpm} ; r$ is the rotation radius of $8.6 \mathrm{~cm} ; h$ is half of the height of cutting ring, $2.55 \mathrm{~cm}$; and $\psi$ is the matric suction, $\mathrm{kPa}, \psi=H / 10$. Based on Eq. (4), the matric suction $\psi$ can be calculated based on Eq. (5). a)

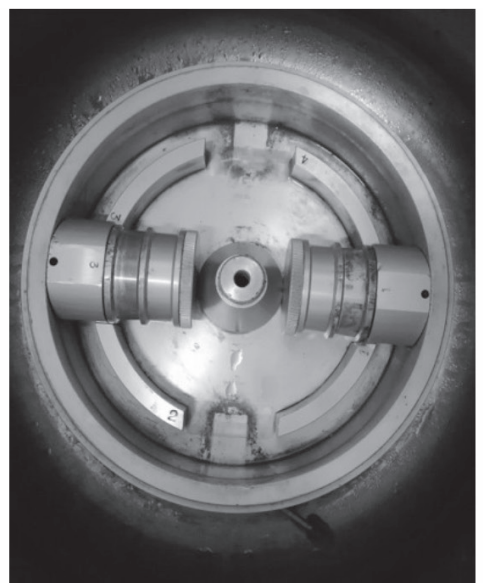

b)

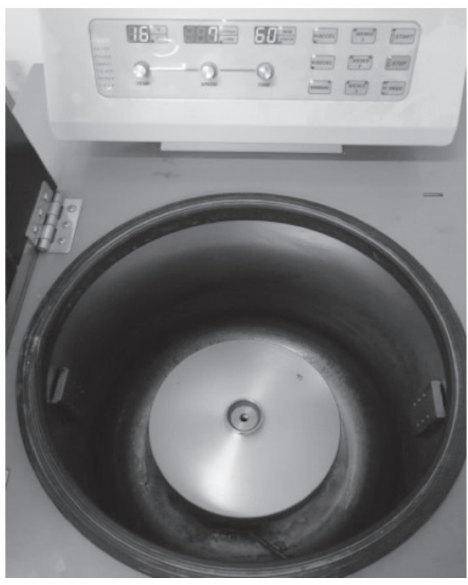

c)

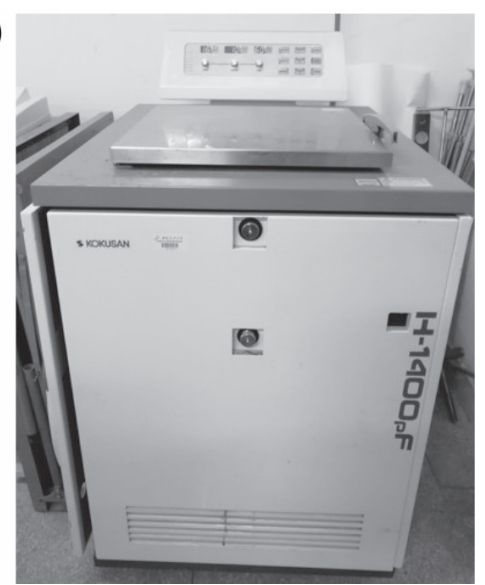

Fig. 1. The H-1400PF SWCC measurement system: a) Put centrifuge rotor into the centrifuge; b) Cover the lid; c) Close the door of the centrifuge. 
Table 3. Parameters of the SWCC and shear strength of the MSW.

\begin{tabular}{|c|c|c|c|c|c|c|c|c|c|c|}
\hline \multirow{2}{*}{\multicolumn{2}{|c|}{$\frac{\text { Waste }}{\text { Compaction }}$}} & \multicolumn{3}{|c|}{ Shallow layer waste } & \multicolumn{3}{|c|}{ Middle layer waste } & \multicolumn{3}{|c|}{ Deep layer waste } \\
\hline & & Low & Moderate & High & Low & Moderate & High & Low & Moderate & High \\
\hline \multicolumn{2}{|c|}{ Dry density $\left(\mathrm{g} \mathrm{cm}^{-3}\right)$} & 0.42 & 0.52 & 0.62 & 0.57 & 0.71 & 0.85 & 0.76 & 0.95 & 1.14 \\
\hline \multirow{5}{*}{$\begin{array}{c}\text { SWCC } \\
\text { parameters }\end{array}$} & $\theta_{s}$ & 0.71 & 0.67 & 0.63 & 0.67 & 0.58 & 0.54 & 0.62 & 0.57 & 0.48 \\
\hline & $\theta_{r}$ & 0.10 & 0.09 & 0.08 & 0.14 & 0.12 & 0.11 & 0.17 & 0.15 & 0.15 \\
\hline & $\alpha$ & 5.11 & 4.03 & 1.58 & 3.66 & 2.97 & 1.22 & 3.66 & 2.90 & 1.53 \\
\hline & $n_{v}$ & 1.41 & 1.32 & 1.32 & 1.46 & 1.30 & 1.30 & 1.38 & 1.26 & 1.24 \\
\hline & $\mathrm{m}$ & 0.29 & 0.24 & 0.24 & 0.32 & 0.23 & 0.23 & 0.27 & 0.21 & 0.19 \\
\hline \multicolumn{2}{|c|}{ Cohesion $(\mathrm{kPa})$} & 18.60 & 23.30 & 28.00 & 16.20 & 20.20 & 24.20 & 0.00 & 0.00 & 0.00 \\
\hline \multicolumn{2}{|c|}{ Friction angle $\left({ }^{\circ}\right)$} & 7.90 & 9.90 & 11.90 & 17.50 & 21.90 & 26.30 & 20.80 & 26.00 & 31.20 \\
\hline \multicolumn{2}{|c|}{ Unit weight $\left(\mathrm{kN} \mathrm{m}^{-3}\right)$} & 6.10 & 9.10 & 15.70 & 9.00 & 11.00 & 16.10 & 10.80 & 12.40 & 16.20 \\
\hline \multicolumn{2}{|c|}{ Permeability $\left(10^{-3} \mathrm{~cm} \mathrm{~s}^{-1}\right)$} & 8.39 & 4.43 & 2.34 & 3.22 & 1.31 & 0.54 & 0.95 & 0.28 & 0.08 \\
\hline
\end{tabular}

Note: The unit weight of waste was obtained from Yang et al. (2016) [3], and the cohesion and friction angle of the waste was obtained from Qiu et al. (2012) [15].

$$
\psi=2.09 \times 10^{-5} N^{2}
$$

As shown in Eq. (5), the matric suction was determined by the rotational speed, and the corresponding volumetric water content under each matric suction was determined through the dry density of the sample and the mass of the sample after each stage revolution speed. The SWCC of the waste sample is obtained.

The waste sample with low compaction in shallow layer was taken as an example to introduce the test process. The saturated waste sample was put into the centrifuge rotor together with the cutting ring, and then the unit was put into the centrifuge, as shown in Fig. 1a). The centrifuge was started after setting the revolution time and speed. Revolution time was set $60 \mathrm{~min}$. Under centrifugal action, the water in the waste sample was thrown out and gathered at the bottom of the centrifuge rotor. Therefore, after each change in rotation speed, the water at the bottom of the rotor was poured out and the weight was recorded. Combined with the dry density of the waste sample, the volumetric water content at each matric suction can be calculated to obtain the SWCC of MSW. For the waste sample with low compaction in shallow layer, the revolution speed is in order: 400, 700, 1000, 1400, 1900, 2200, 3800, and $4900 \mathrm{rpm}$. The corresponding matric suction is $3,10,21,41,75$, 101,302 , and $502 \mathrm{kPa}$, respectively.

It was assumed that the waste in the Jiangcungou landfill had moderate compaction with the dry density of $0.95 \mathrm{~g} / \mathrm{cm}^{3}$ (shallow layer), $0.71 \mathrm{~g} / \mathrm{cm}^{3}$ (middle layer), and $0.52 \mathrm{~g} / \mathrm{cm}^{3}$ (deep layer). The dry density of waste with low and high compaction is shown in Table 3. The SWCC of these samples was measured in a laboratory using a centrifuge and the result is shown in Fig. 2.
The result of MSW sample in shallow layer is taken as an example to show the effect of compaction degree on the SWCC. As shown in Fig. 2, the volumetric water content decreased with the increase in matric suction, and the SWCC of waste with different compaction degrees gradually converged with the increase in matric suction when the matric suction was greater than $\mathrm{S}_{2}$. When the matric suction was about $10^{4} \mathrm{kPa}$, the SWCC of waste with different compaction degrees almost converged to a single point. The figure also shows that the volumetric water content of MSW with low compaction was the largest when the matric suction was less than $\mathrm{S}_{1}$. In addition, MSW with low compaction own the minimum volumetric water content when the matric suction is more than $\mathrm{S}_{2}$. The MSW with low compaction had high porosity, large pore size, and the large saturated water content (i.e., large initial volumetric water content). As the matric suction increased, the MSW with low compaction lost its water relatively quickly at small negative pressure heads. The opposite effect occurs in MSW with high compaction. The same observations were made in the MSW from the middle and deep layers.

As mentioned above, the SWCC of waste with different compaction degrees and the same component almost converged to one point when the matric suction was about $10^{4} \mathrm{kPa}$. For the convenience of comparison, a line with a volume water content of 0.15 is shown in Fig. 2. The volumetric water content of the converge point was less than 0.15 in the shallow layer, nearly 0.15 in the middle layer, and greater than 0.15 in the deep layer. This result may be related to the residual water content of the MSW.

The SWCC fitting parameters of the waste with different degrees of compaction are shown in Table 3, and the SWCC parameters versus the dry density 


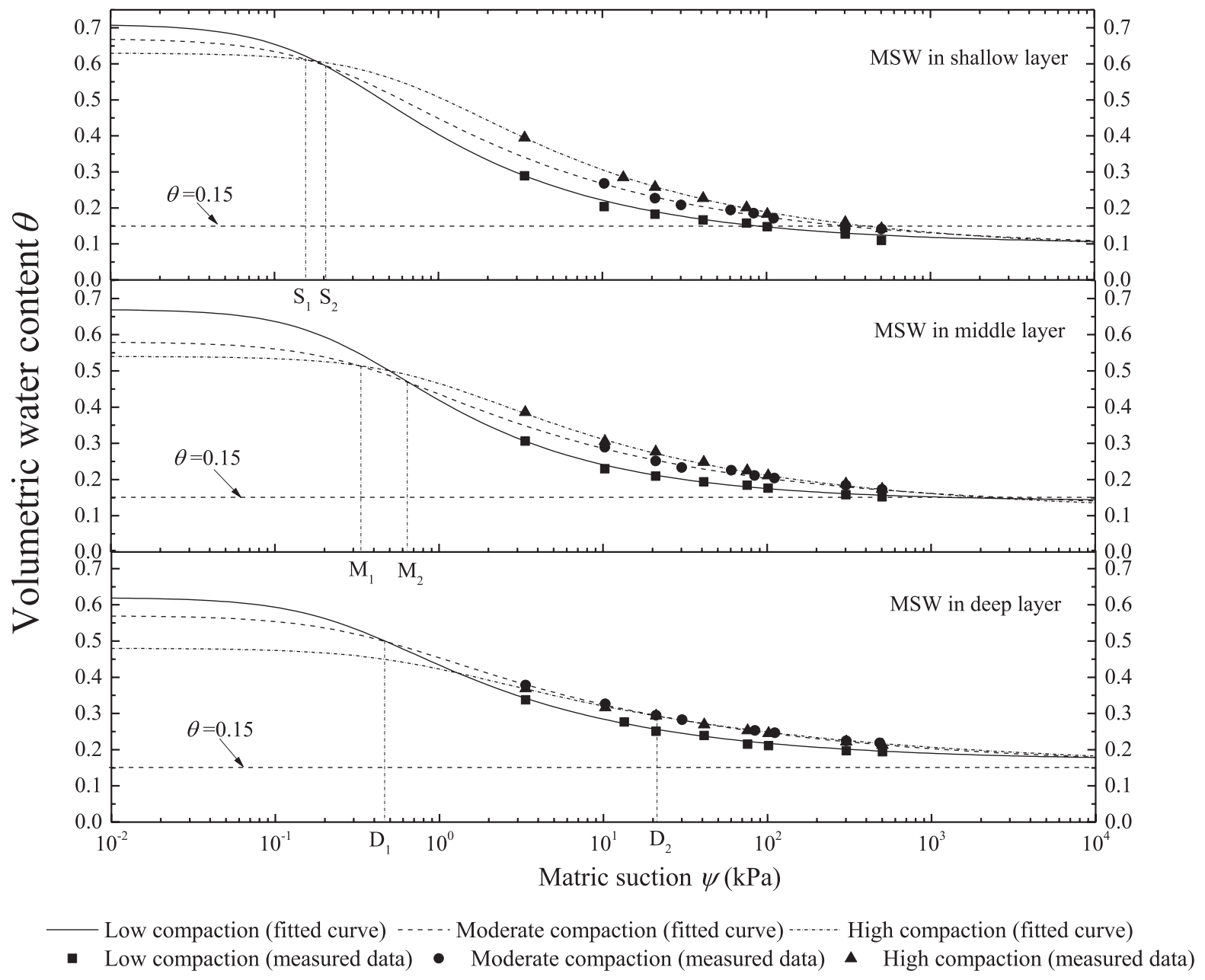

Fig. 2. SWCC of MSW under low, moderate, and high compaction.

are shown in Fig. 3. The parameters of SWCC are closely related to the degree of compaction. As shown in Fig. 3, the saturated water content, $\theta_{s}$, decreased with increasing dry density. This is because the saturated volumetric water content, $\theta_{s}$, should be equal to the porosity, $n$, and the waste with high compaction density always has low porosity [20]. Thus, for the waste with the same compaction, its saturated water content, $\theta_{s}$, decreases with increasing dry density. Fig. 3 also demonstrates that the $\alpha$ value decreased greatly with the increase in dry density, and that it decreased fastest when the waste was from the shallow layer and slowest when the waste was from the deep layer. In addition, $n_{v}$ value decreased with the increase in dry density as shown in Fig. 3 . The parameter, $n_{v}$, represents the gradient of the SWCC, and the larger value of $n_{v}$ indicates the steeper gradient of the SWCC. Thus, for the waste with low compaction, the volumetric water content decreases rapidly with increasing matric suction. Additionally, the variation in the residual water content, $\theta_{r}$, was small with the increase in dry density when the waste was in the same layer. The residual water content, $\theta_{r}$, is in the range of $0.08-0.10$ when the waste was from the shallow layer, in the range of 0.11-0.14 when the waste was from the middle layer, and in the range of $0.15-0.17$ when the waste was from the deep layer. This is because $\theta_{r}$ is closely related to the composition of the waste and is nearly the same for waste with similar compositions [20].

\section{Geometric Model}

Based on the currently available literature, Fig. 4 shows a geometric model of the Xi'an Jiangcungou landfill in 2014, and the slope ratio is approximately 1:4 [25]. A portion of the cross-section including the slope was selected because this study primarily focuses on the stability of the landfill slope. As shown in Fig. 4, there are eight layers of waste, and the thickness of each waste layer is approximately $10 \mathrm{~m}$. As shown in Fig. 5, an intermediate cover of compacted loess with a thickness of approximately $0.3 \mathrm{~m}$ lies between the two layers of waste. According to the landfill process, from the bottom to the top and above the foundation of the first to third layers, the forth to sixth layers and seventh and eighth layers are termed the deep layer, the middle layer, and the shallow layer waste.

The slope ratio of the failed landfills shown in Tables 1 and 2 falls in the range of 1:1.2-1:3.5. In this study, the slope ratio of the Jiangcungou landfill was 


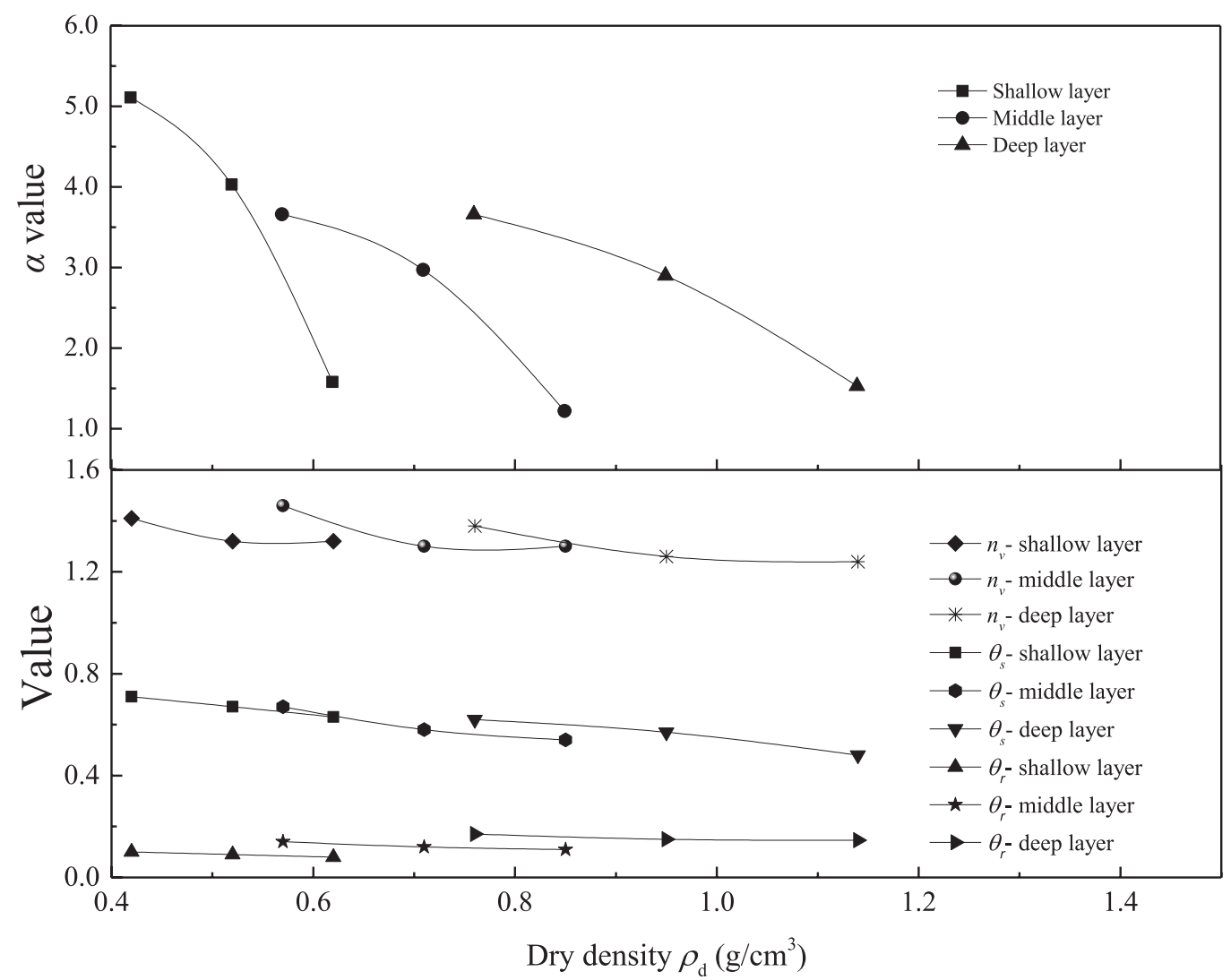

Fig. 3. Parameters of the soil water characteristic curve vs. dry density.

changed to explore the effect of the slope ratio on landfill stability. Five slope ratios, 1:2.0, 1:2.5, 1:3.0, $1: 3.5$, and 1:4.0, were used in this study.

\section{Parameters for Seepage and the Stability Analysis}

The saturated permeability coefficient of loess as an intermediate cover was found to be $8.37 \times 10^{-8} \mathrm{~cm} / \mathrm{s}$ by testing in situ [26]. Some permeability coefficients of waste in landfills are summarized, and the permeability coefficients decrease with the increase in dry density, as shown in Fig. 6. This is because MSW is a particulate material and a large proportion of the components have a high void ratio and high compressibility, and compaction processes will reduce pore size and change the geometry and continuity of pores, resulting in a decreasing area of flow [31, 32]. In addition, permeability is dependent largely on the pore structure of waste in landfills [33]. Thus, as the MSW compacted

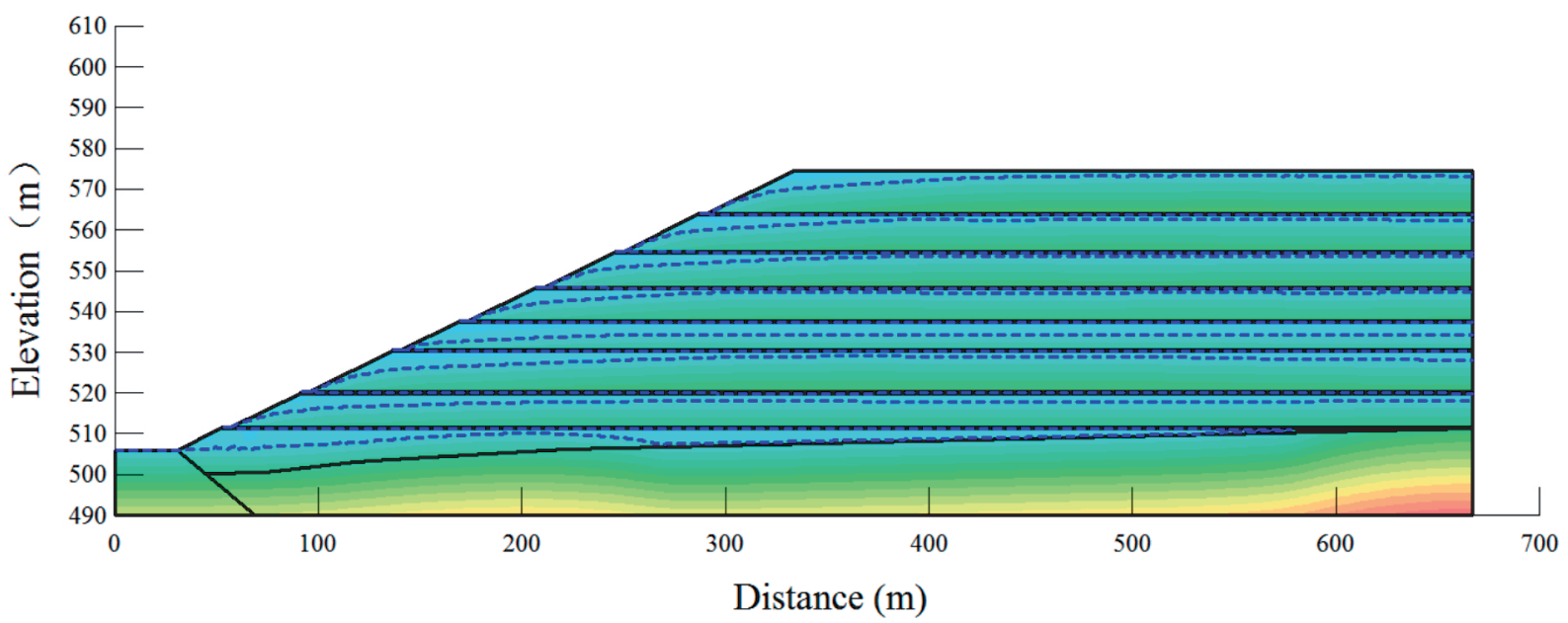

Fig. 4. The initial water level of the landfill with failed drainage, medium compaction and the slope of 1:4.0. 


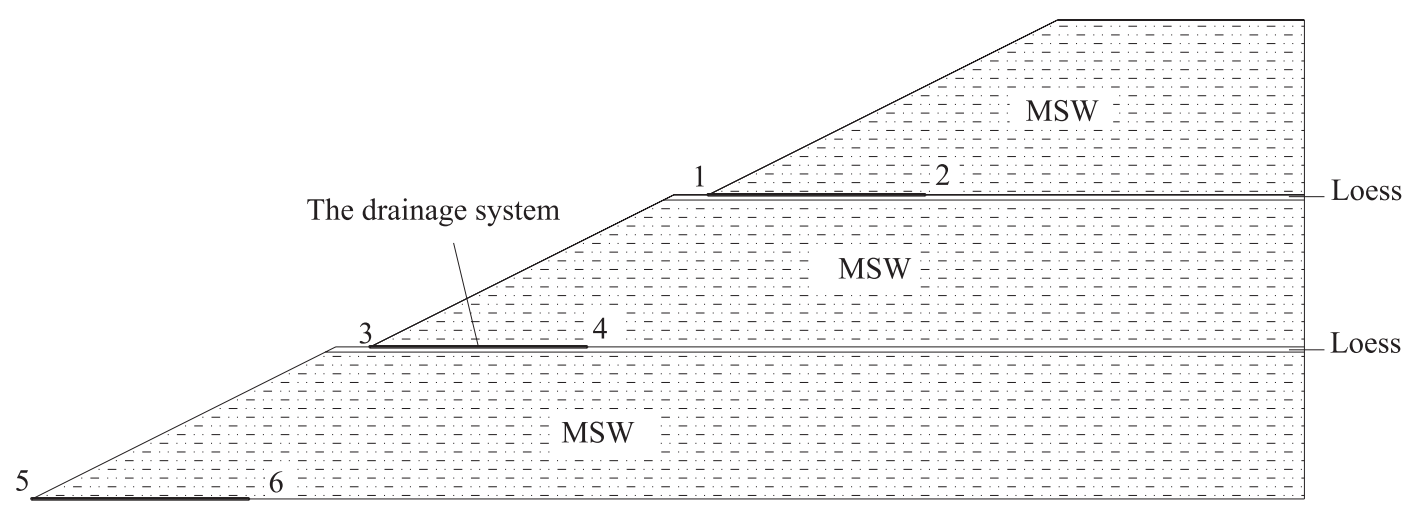

Fig. 5. Schematic diagram of the partial slope.

density increases, the coefficient of permeability values of the MSW samples decrease. Furthermore, the common logarithm of the permeability coefficient has a linear function relationship with the dry density according to the previous study and the fitting formula is shown in Eq. (6).

$$
\lg k_{s}=-2.778 \rho_{d}-0.909
$$

Here, $k_{\mathrm{s}}$ is the saturated hydraulic conductivity, $\mathrm{cm} / \mathrm{s}$; and $\rho_{d}$ is the dry density, $\mathrm{g} / \mathrm{cm}^{3}$. The saturated hydraulic conductivity $k_{\mathrm{s}}$ of waste with different compaction degrees is determined according to Eq. (6). The hydraulic conductivity $k$ is determined according to Eqs. (2) and (3).

Shear strength may be the most important mechanical property of waste in landfill projects [12]. Both age and compaction density of waste have an effect on shear strength. Fig. 7 summarizes the variation in the shear strength parameters with the age of the waste based on others' research. The friction angle ranges from $7.4^{\circ}$ to $48.0^{\circ}$, and the cohesion ranges from $0 \mathrm{kPa}$ to $43.4 \mathrm{kPa}$. It is obvious that the friction angle increases with landfill age, and the cohesion decreases with landfill age. That is, aged MSW samples often have lower values of the internal friction angle and higher values of cohesion. In addition, the effect of the compaction density on the shear resistance of the waste can be significant [38]. There was a modest trend of increasing friction angle and cohesion with increasing compaction density [39]. Based on the above analysis, the shear strength parameters of the waste are shown in Table 3. The parameters of loess for cohesion, friction angle, and unit weight were $19 \mathrm{kPa}, 22^{\circ}$, and $30 \mathrm{kN} / \mathrm{m}^{3}$, respectively [25].

\section{Boundary Conditions}

The continuous rain data from 1960 to 2015 in Xi'an city was collected for this study. A rainfall event is from

Table 4. Working condition design of the single variable changing.

\begin{tabular}{|c|c|c|c|c|c|c|}
\hline Factors & $\begin{array}{c}\text { Rainfall } \\
(\mathrm{mm} / 72 \mathrm{~h})\end{array}$ & Rainfall patterns & Slope & Drainage & Compaction & $\begin{array}{l}\text { Number of } \\
\text { combination }\end{array}$ \\
\hline \multirow{3}{*}{ Rainfall } & 183.16 & \multirow{3}{*}{$\begin{array}{l}\text { Advanced rainfall pattern; } \\
\text { Normal rainfall pattern; } \\
\text { Delayed rainfall pattern }\end{array}$} & \multirow{3}{*}{$1: 4.0$} & \multirow{3}{*}{ Failed drainage } & \multirow{3}{*}{ Moderate } & \multirow{3}{*}{9} \\
\hline & 137.61 & & & & & \\
\hline & 92.09 & & & & & \\
\hline \multirow{5}{*}{ Slope } & \multirow{5}{*}{ None } & \multirow{5}{*}{-} & $1: 4.0$ & \multirow{5}{*}{ Good drainage } & \multirow{5}{*}{ Moderate } & \multirow{5}{*}{5} \\
\hline & & & $1: 3.5$ & & & \\
\hline & & & $1: 3.0$ & & & \\
\hline & & & $1: 2.5$ & & & \\
\hline & & & $1: 2.0$ & & & \\
\hline \multirow{3}{*}{$\begin{array}{c}\text { Compaction } \\
\text { degree }\end{array}$} & \multirow{3}{*}{ None } & \multirow{3}{*}{-} & \multirow{3}{*}{$1: 3.0$} & \multirow{3}{*}{ Good drainage } & Low & \multirow{3}{*}{3} \\
\hline & & & & & Moderate & \\
\hline & & & & & High & \\
\hline Drainage & None & - & $1: 3.0$ & $\begin{array}{l}\text { Good drainage; Moderate } \\
\text { drainage; Failed drainage }\end{array}$ & Moderate & 3 \\
\hline
\end{tabular}

Note: The good, moderate, and failed drainage means a drainage system of $50 \mathrm{~m}, 25 \mathrm{~m}$, and no drainage system respectively. 


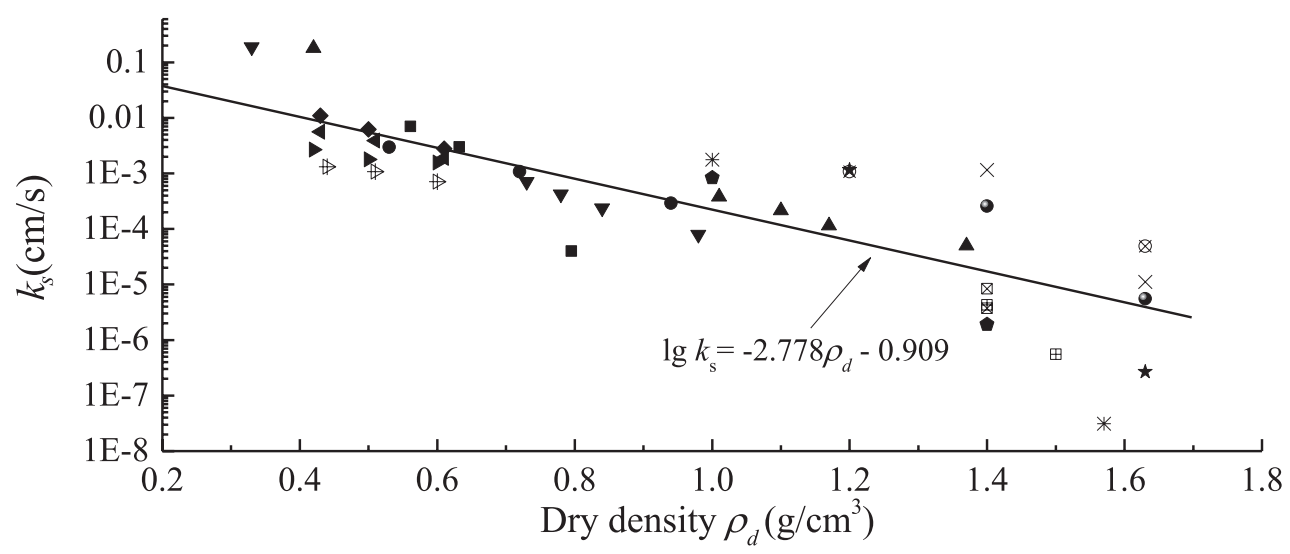

- Breitmeyer and Benson (2011) - Jang et al.(2002) \ Reddy et al. (2009)-Fresh MSW

> Reddy et al. (2009)-17 Months • Hossain and Haque (2009)-Phase 1

4 Hossain and Haque (2009)-Phase 2 Hossain and Haque (2009)-Phase 3

$\star$ Hossain and Haque (2009)-Phase 4 * Jie et al. (2013)-specimen 1 • Jie et al. (2013)-specimen 2

- Jie et al. (2013)-specimen $3 \rightarrow$ Jie et al. (2013)-specimen $4 \times$ Jie et al. (2013)-specimen 5

* Jie et al. (2013)-specimen $6 \bowtie$ Jie et al. (2013)-specimen $7 \otimes$ Jie et al. (2013)-specimen 8

Fig. 6. Saturated hydraulic conductivity $k_{\mathrm{s}}$ of waste in landfills vs. dry density [12, 27-30].

the beginning, when the daily rainfall was not less than $0.1 \mathrm{~mm}$, to the end, when the daily rainfall was less than $0.1 \mathrm{~mm}$. The statistics indicated that there were 524 continuous rain events in Xi'an with a duration of 3 to 17 days from 1960 to 2015 . Three-day continuous rainfall events were the most repeated durations in the collected rainfall data. There were 247 continuous rain events with a duration of three days, and this accounted for $46.6 \%$. Therefore, in this study, three days (i.e., $72 \mathrm{~h}$ ) was selected to represent the duration of the rainfall patterns. The maximum of the threeday rainfall during events during these 55 years was $111.6 \mathrm{~mm}$ in September 1986, and the minimum was $0.3 \mathrm{~mm}$ in November 1964. Hydrological frequency

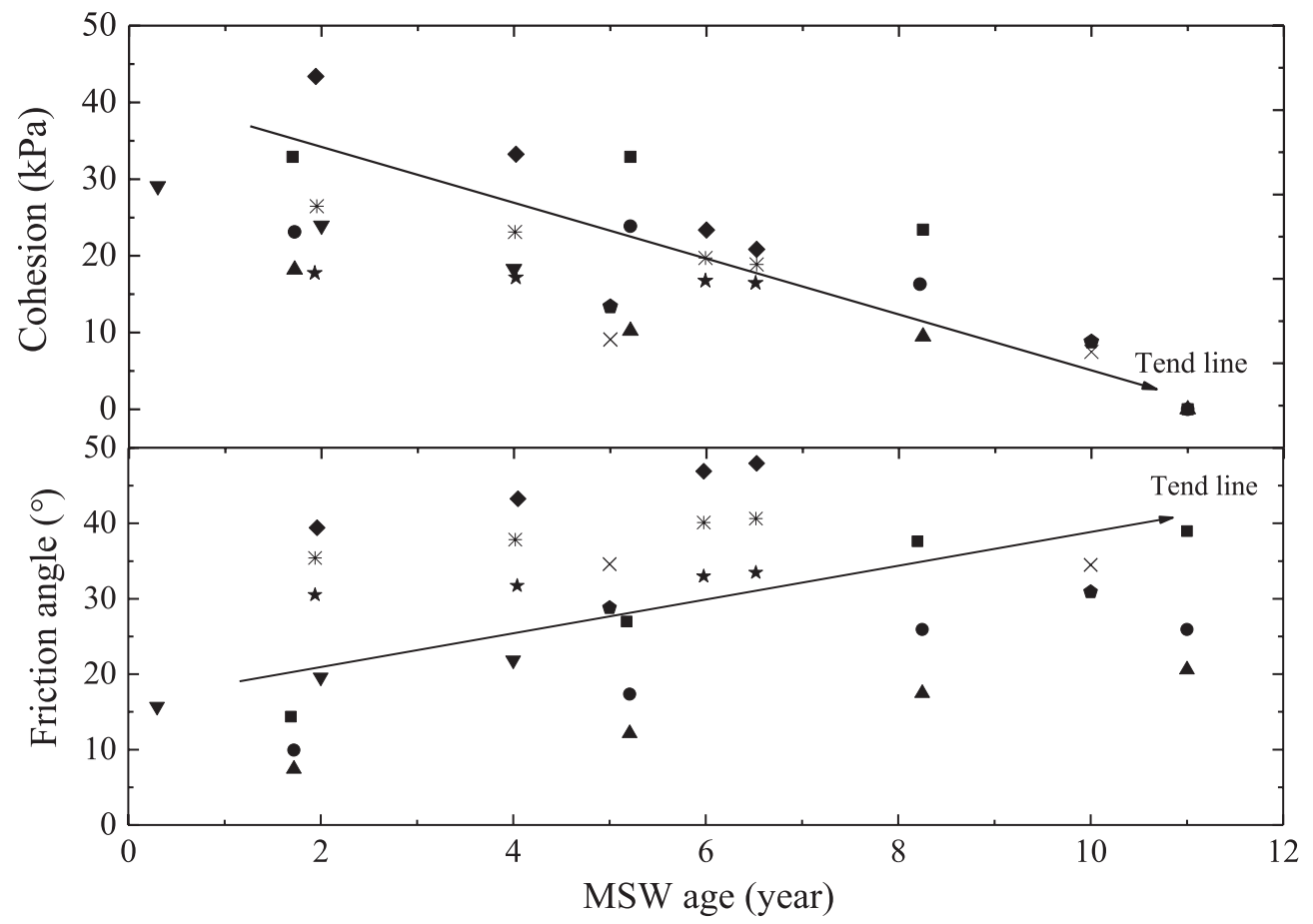

- Zhan et al. (2008)-Axial strain 20\% - Zhan et al. (2008)-Axial strain 10\% $\Delta$ Zhan et al. (2008)-Axial strain 5\%

- Gomes et al. (2013)-Axial strain 25\% * Gomes et al. (2013)-Axial strain 20\% * Gomes et al. (2013)-Axial strain 15\%

- lv et al. (2015)-Consolidated undrained $\times$ lv et al. (2015)-Consolidated drained $\nabla$ Feng et al. (2016)

Fig. 7. Variation in the shear strength parameters of the MSW related to age [34-37]. 
analysis software was used to debug the statistical data, and the fitted curve method was used to draw the Pearson $\amalg$ curve. The design values of the total rainfall for three consecutive days with a recurrence period of 1 year, 10 years, and 100 years were $92.09 \mathrm{~mm}, 137.61 \mathrm{~mm}$, and $183.16 \mathrm{~mm}$, respectively.

The safety factors were calculated when the precipitation for the three days (i.e., 72 hours) was $92.09 \mathrm{~mm}, 137.61 \mathrm{~mm}$, and $183.16 \mathrm{~mm}$. The 72 hours duration was divided into equal time intervals for each rainfall intensity at 4.8-hour intervals. Slope instability is not only related to rainfall intensity and rainfall duration but also related to rainfall patterns [15].

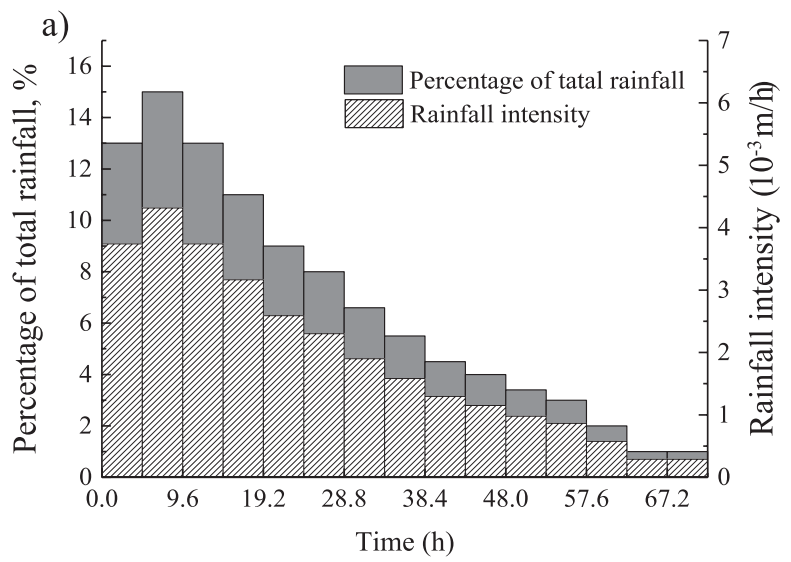

b)

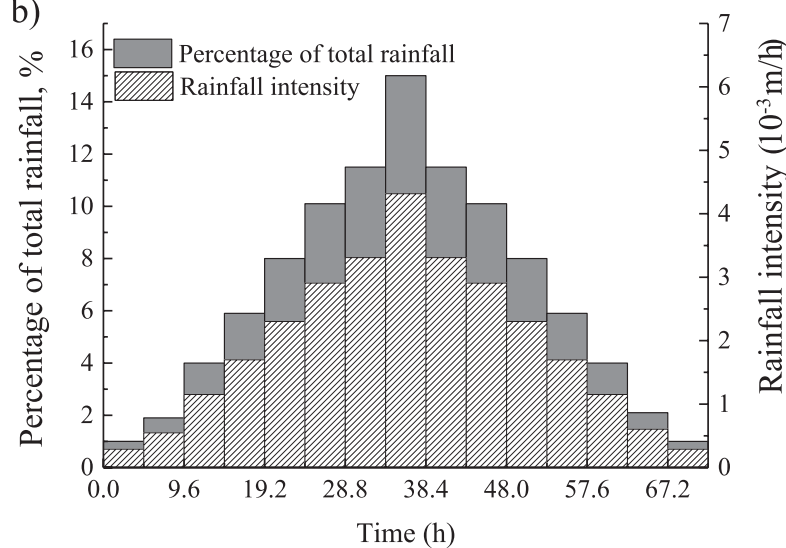

c)

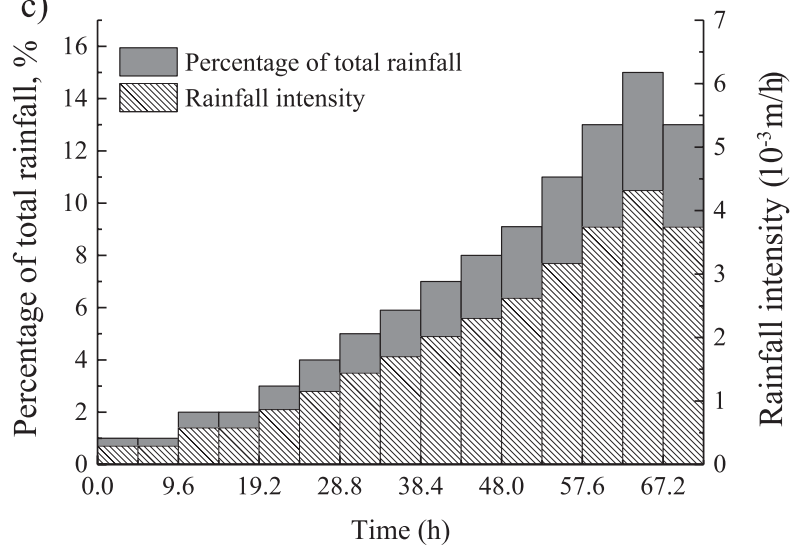

Fig. 8. Idealized rainfall patterns and rainfall intensity with total rainfall of $92.09 \mathrm{~mm}$ in $72 \mathrm{~h}$ : a) advanced rainfall pattern, b) normal rainfall pattern, and c) delayed rainfall pattern.
Rainfall patterns can be categorized into three different groups: advanced rainfall patterns, normal rainfall patterns, and delayed rainfall patterns [40]. The three recognized rainfall patterns are shown in Fig. 8. The values of $92.09 \mathrm{~mm}, 137.61 \mathrm{~mm}$, and $183.16 \mathrm{~mm}$ were then distributed based on the idealized rainfall patterns. This was multiplied by the idealized rainfall percentage for each time interval for the three recognized rainfall patterns [40]. To obtain the rainfall intensity, the total rainfall in each time interval was divided by $4.8 \mathrm{~h}$. For example, Fig. 8 shows the rainfall intensity with a total rainfall of $92.09 \mathrm{~mm}$ in $72 \mathrm{~h}$.

Due to the deep groundwater level at the Jiangcungou landfill, the impact of groundwater on the landfill was not considered. In addition, the moisture generated by waste degradation during the transient analysis was minimal since the transient analysis lasted only 72 hours. Therefore, it was ignored. Thus, rainfall was the only water that entered the landfill. The rainfall was distributed at the top of the landfill and on the slope when the rainfall was considered.

In the Jiangcungou landfill, the bottom of each waste layer has the gravel guide layers as the drainage system near the foot of the downstream slope to collect and drain the leachate, as shown in Fig. 5. In the finite element model, the gravel guide layers are replaced by the lines, such as the bold lines 1-2, 3-4, and 5-6 in Fig. 5. In addition, the bold lines 1-2, 3-4, 5-6 are $50 \mathrm{~m}$ at good drainage, $25 \mathrm{~m}$ at moderate drainage, and no drainage system at failed drainage, respectively. It is assumed that the drainage system would exhibit free flow where the pressure head would be $0 \mathrm{~m}$.

The initial water level of the landfill is obtained by simulating the life of the landfill. Taking the landfill with failed drainage, medium compaction and the slope of 1:4.0 for an example, the initial water level of the landfill is shown in Fig. 4. For each layer, the blue lines represent phreatic lines at the initial condition in Fig. 4, where the waste below the phreatic line is saturated and above the phreatic line is unsaturated. In addition, it was assumed that the critical slip surface would not pass through the initial dam or the foundation at the bottom of the landfill due to their high shear strengths relative to the MSW [37].

\section{Working Condition Design}

In this study, the effects of the factors (drainage, rainfall, slope ratio, and compaction degree) on the safety factor of the landfill are discussed, including the one factor and the combination of several factors. The working condition design of discussing the effect of one factor on landfill stability is shown in Table 4 . In addition, the effect of a combination of several factors on landfill stability is discussed using the orthogonal experiment design method.

Four factors and three levels were used to evaluate the influence of the combination of several factors (rainfall, slope ratio, drainage system, and compaction 
Table 5. The orthogonal experimental table.

\begin{tabular}{|c|c|c|c|c|c|}
\hline \multirow{2}{*}{ Number } & \multicolumn{4}{|c|}{ Factors } & \multirow{2}{*}{$\begin{array}{c}\text { Minimum } \\
\text { factor of safety }\end{array}$} \\
\hline & A Rainfall (mm/72 h) & B Slope & C Drainage & D Compaction & \\
\hline 1 & $92.09(1)$ & $1: 3.0(1)$ & Good (1) & Low (1) & 1.28 \\
\hline 2 & 92.09 & $1: 3.5(2)$ & Moderate (2) & Moderate (2) & 1.78 \\
\hline 3 & 92.09 & $1: 4.0(3)$ & Failed (3) & High (3) & 1.79 \\
\hline 4 & $137.61(2)$ & $1: 3.0$ & Moderate & High & 1.70 \\
\hline 5 & 137.61 & $1: 3.5$ & Failed & Low & 1.19 \\
\hline 6 & 137.61 & $1: 4.0$ & Good & Moderate & 1.61 \\
\hline 7 & $183.16(3)$ & $1: 3.0$ & Failed & Moderate & 1.28 \\
\hline 8 & 183.16 & $1: 3.5$ & Good & High & 1.87 \\
\hline 9 & 183.16 & $1: 4.0$ & Moderate & Low & 1.43 \\
\hline$\overline{\mathrm{k}}_{1}$ & 1.62 & 1.42 & 1.59 & 1.30 & - \\
\hline$\overline{\mathrm{k}}_{2}$ & 1.50 & 1.61 & 1.64 & 1.56 & - \\
\hline$\overline{\mathrm{k}}_{3}$ & 1.53 & 1.61 & 1.42 & 1.79 & - \\
\hline $\mathrm{R}$ & 0.12 & 0.19 & 0.22 & 0.49 & - \\
\hline
\end{tabular}

degree) on the safety factor in the orthogonal experiment design method. The three-day continuous rainfall recurrence period of 100 years, 10 years, and 1 year in Xi'an were selected, and the corresponding rainfall amounts of the three days were $183.16 \mathrm{~mm}$, $137.61 \mathrm{~mm}$, and $92.09 \mathrm{~mm}$, respectively. The common slope ratios of $1: 3.0,1: 3.5,1: 4.0$ were selected. The compaction conditions chosen were low compaction, moderate compaction (the degree of compaction at Xi'an Jiangcungou), and high compaction. The drainage systems used were good, moderate, and failed. In addition, the good, moderate, and failed drainage meant the drainage systems of $50 \mathrm{~m}, 25 \mathrm{~m}$, and no drainage system, respectively. The four factors of rainfall (factor A), slope ratio (factor B), drainage (factor C), and compaction (factor D) are independent. Thus, the orthogonal experiment table $\mathrm{L}_{9}\left(3^{4}\right)$ was used to array the factors in this study. The commonly used orthogonal table has been formulated by mathematicians. The orthogonal factorial design in this manuscript is shown in Table 5. Each row of the orthogonal array represents a run [19].

\section{Results and Discussion}

\section{Effects of Rainfall}

Figs 10 and 11 show the effect of rainfall on the safety factor using the slope ratio (1:4) of the Jiangcungou landfill as an example. Figs 10(a-c) shows the safety factor over time with the rainfall amounts of $92.09 \mathrm{~mm}, 137.61 \mathrm{~mm}$, and $183.16 \mathrm{~mm}$ during the three rainfall patterns. The safety factor of the initial state (i.e., $\mathrm{t}=0 \mathrm{~h}$ ) is 1.85 . As the rainfall time increases, the stability safety factor of the landfill continues to decrease, and the safety factor reaches a minimum at 72 hours. This is because rainfall infiltration increases the slope quality. The pore water pressure in the waste pile also increased with rainfall infiltration, and the increased pore water pressure reduced the effective stress of the geologic body, creating further instability [4].

As shown in Fig. 9, the safety factor will drop sharply in a period of time. Among the three rainfall patterns, the phenomenon of a sharp decline in the safety factor occurred first in the advanced rainfall pattern, followed by the normal rainfall pattern, and occurred latest in the delayed rainfall pattern. Using Fig. 9b) as an example, the safety factor dropped sharply at $16 \mathrm{~h}$ in the advanced rainfall pattern, at $32 \mathrm{~h}$ in the normal rainfall pattern, and at $48 \mathrm{~h}$ in the delayed rainfall pattern. This was related to the time when the peak rainfall occurred, and the peak rainfall of the advanced rainfall pattern occurred early, followed by the normal rainfall pattern, and the normal rainfall pattern occurred later.

The minimum safety factors in the three rainfall patterns were nearly constant at the same slope ratios and total rainfall amounts. When the rainfall was $92.09 \mathrm{~mm}$, $137.61 \mathrm{~mm}$, and $183.16 \mathrm{~mm}$, and the corresponding minimum safety factors were $1.56,1.48$, and 1.42 at 72 hours, respectively. When the rainfall was $183.16 \mathrm{~mm}$, the safety factor dropped the most, dropping by 0.43 during the rainfall. When the rainfall was $92.09 \mathrm{~mm}$, the safety factor dropped the least, dropping by approximately 0.29 during the rainfall event. The magnitude of the decline in the safety factor increased with increasing rainfall. In addition, at the same time, the safety factors were the smallest, the second, and 
the largest in the advanced, normal, and delayed rainfall patterns, respectively, in the same total rainfall, as shown in Fig. 9. Using Fig. 9a) as an example, the safety factors were $1.61,1.49$, and 1.45 in the advanced, normal, and delayed rainfall patterns, respectively, at $48 \mathrm{~h}$.

Fig. 10 shows that the safety factors decreased with time at the Jiangcungou landfill in the advanced, normal, and delayed rainfall patterns. In a certain rainfall pattern, the large rainfall amounts tend to have a small safety factor at the same time. Using Fig. 10a) as an example, in the advanced rainfall patterns when the time was 32 hours, the safety factors were 1.68,
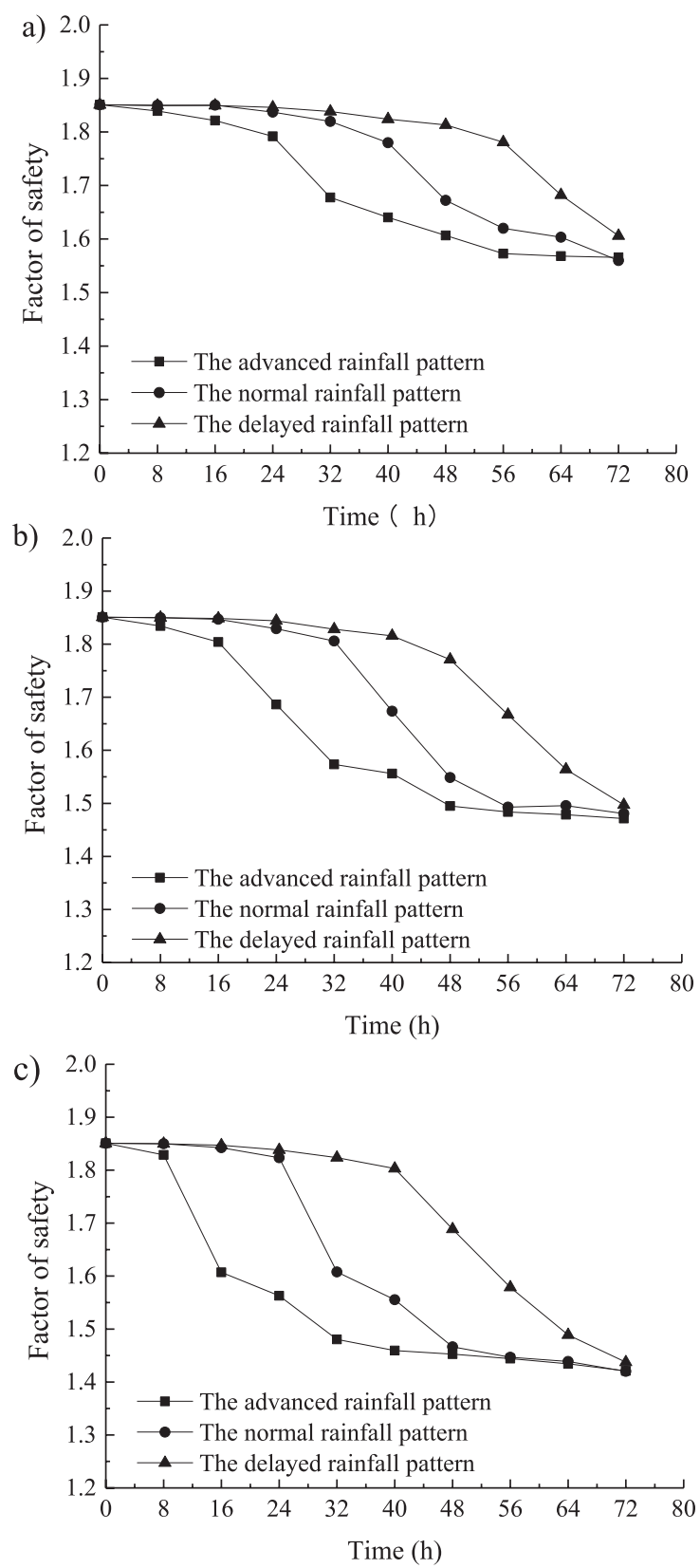

Fig. 9. Variation in the safety factor with time for the different rainfall intensities at the Jiangcungou landfill: a) total rainfall of $92.09 \mathrm{~mm}$ within 72 hours, b) total rainfall of $137.61 \mathrm{~mm}$ within 72 hours, and c) total rainfall of $183.16 \mathrm{~mm}$ within 72 hours.
1.57, and 1.48 during rainfall events of $92.09 \mathrm{~mm}$, $137.61 \mathrm{~mm}$, and $183.16 \mathrm{~mm}$, respectively. In addition, the phenomenon of a sharp drop in the safety factor tended to occur early in the case of a large rainfall intensity in a certain rainfall pattern.

\section{Effects of Slope Ratio, the Drainage System and Compaction}

It was assumed that there was no rainfall under normal operating conditions. When the drainage system was good, the safety factors were 2.07, 2.02, 1.81, 1.67 , and 1.41 under normal operating conditions with
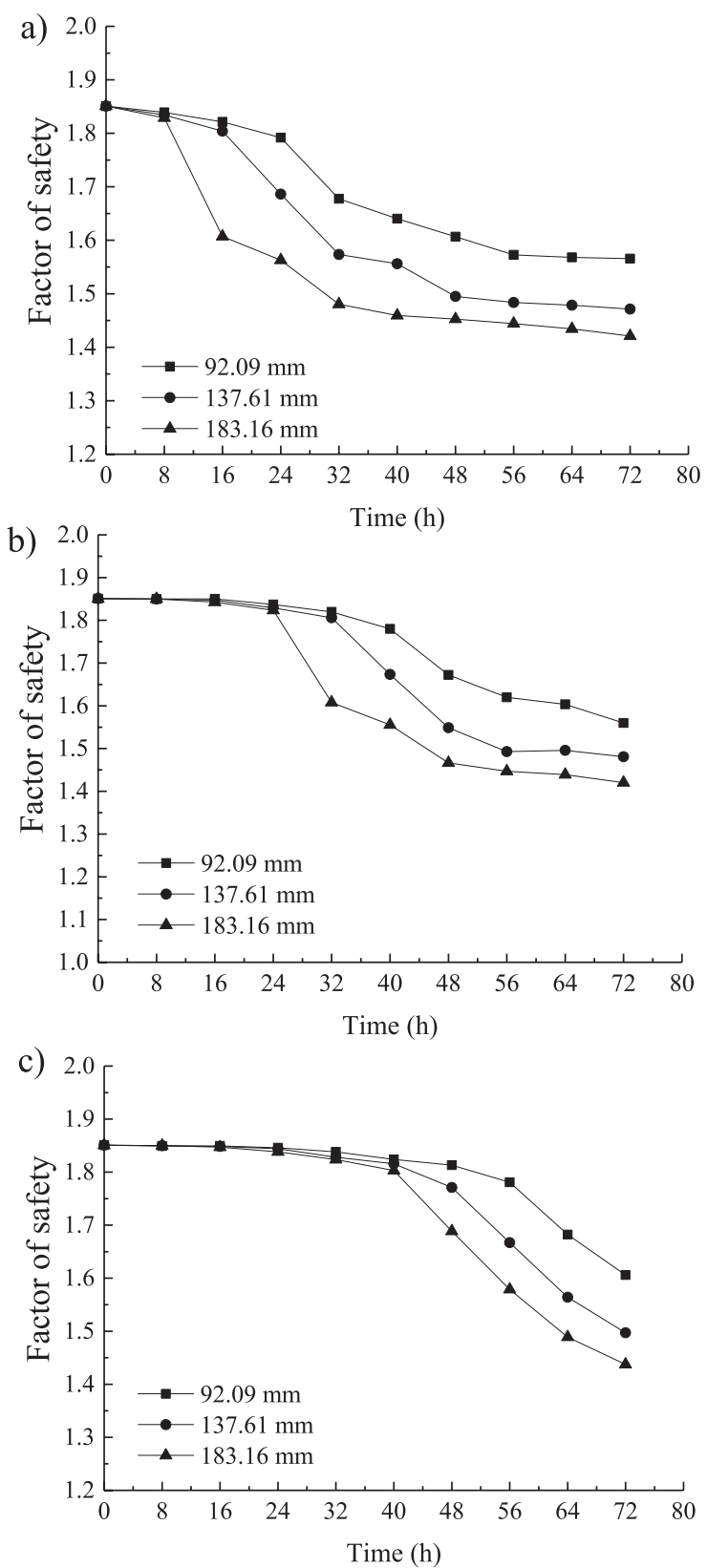

Fig. 10. Variation in the safety factor with time during different rainfall patterns at the Jiangcungou landfill: a) the advanced rainfall pattern, b) the normal rainfall pattern, and c) the delayed rainfall pattern. 
slopes of 1:4.0, 1:3.5, 1:3.0, 1:2.5, and 1:2.0, respectively. Obviously, the steeper the slope was, the smaller the safety factor tended to be. For the landfill stability, the more subdued the slope the better. However, a gentle slope would come at the expense of reducing the storage capacity. Therefore, both the landfill storage capacity and stability should be considered in the design of a landfill site.

When the landfill is under slope of 1:3.0, the safety factors of the landfill with good, moderate and failed drainage system are $1.81,1.75$, and 1.70 , respectively. Compared with failed drainage system, the safety factor of the landfill with a good and moderate drainage system increased by 0.11 and 0.05 respectively. It can be seen that the drainage system did not have an obvious influence on the factor safety of a landfill effectively when there was no rainfall.

The safety factors of the landfill with low compaction, moderate compaction, and high compaction are $1.27,1.81$, and 1.88, respectively. A landfill with a higher compaction tended to have larger safety factors. This is because compaction energy enables the waste to become denser, and for the waste with the same composition, the denser specimen exhibited a higher shear resistance [41].

According to the project profile and Chinese code [42], a landfill will be safe when the safety factor of the landfill slope is greater than 1.35. More precisely, it is assumed that landfill instability will occur when the safety factor is less than 1.35 under normal operating conditions. Thus, when landfill is under the good drainage, the landfill was safe when the slope ranged from 1:2.0 to 1:4.0. When landfill is under the slope of 1:3.0 and the moderate compaction, the landfill with good, moderate and failed drainage system was safe. When landfill is under the slope of 1:3.0 and good drainage, the landfill with moderate compaction, and high compaction was safe. Therefore, one adverse factor may not directly lead to landfill instability.

\section{The Evaluation of Factors that Affect the Safety Factor}

The nine working conditions designed in Table 5 were calculated using the finite element software. The minimum safety factor for the nine combinations of four factors is also shown in Table 5. Among the nine working conditions, the working condition of number 5 (i.e. rainfall of $137.61 \mathrm{~mm}$ in three days, a slope ratio of 1:3.5, a failed drainage system, and low compaction) was the most dangerous, and the minimum factor of safety was 1.19. Additionally, the working condition of number 8 (i.e., rainfall of $183.16 \mathrm{~mm}$ in three days, a slope ratio of 1:3.5, a good drainage system, and high compaction) was the safest, and the minimum safety factor was 1.87 .

The parameters of $\overline{\mathrm{k}}_{1}, \overline{\mathrm{k}}_{2}, \overline{\mathrm{k}}_{3}$, and $\mathrm{R}$ is also shown in Table 5. The factor of A (i.e., rainfall) is used as an example to illustrate the calculation method of $\overline{\mathrm{k}}_{1}, \overline{\mathrm{k}}_{2}$, $\overline{\mathrm{k}}_{3} \cdot \overline{\mathrm{k}}_{1 \mathrm{~A}}$ is equal to $\mathrm{k}_{1 \mathrm{~A}} / 3$. In addition, $\mathrm{k}_{1 \mathrm{~A}}$ is the sum of the minimum safety factors when the factor of $\mathrm{A}$ (i.e., rainfall) is 1 (i.e., $92.09 \mathrm{~mm}$ ). That is the sum of the minimum safety factors under the condition of numbers 1,2 , and 3 in Table 5 (i.e., $\mathrm{k}_{1 \mathrm{~A}}=1.28+1.78+1.79$ $=4.85$ ).

In the same way, $\overline{\mathrm{k}}_{2 \mathrm{~A}}$ is equal to $\mathrm{k}_{2 \mathrm{~A}} / 3$, and the $\mathrm{k}_{2 \mathrm{~A}}$ is the sum of the minimum safety factors when the factor of A (i.e., rainfall) is 2 (i.e., $137.61 \mathrm{~mm}$ ). That is the sum of the minimum safety factors under the condition of numbers 4, 5, and 6 in Table 5 (i.e., $\mathrm{k}_{2 \mathrm{~A}}=1.70+1.19$ $+1.61=4.50) \cdot \overline{\mathrm{k}}_{3 \mathrm{~A}}$ is equal to $\mathrm{k}_{3 \mathrm{~A}} / 3$, and $\mathrm{k}_{3 \mathrm{~A}}$ is the sum of the minimum safety factors when the factor of $\mathrm{A}$ (i.e., rainfall) is 3 (i.e., $183.16 \mathrm{~mm}$ ). That is the sum of minimum safety factors under the condition of numbers 7,8 , and 9 in Table 5 (i.e., $\mathrm{k}_{3 \mathrm{~A}}=1.28+1.87+1.43=4.58$ ). The values of $\overline{\mathrm{k}}_{1 \mathrm{~B}}, \overline{\mathrm{k}}_{2 \mathrm{~B}}, \overline{\mathrm{k}}_{3 \mathrm{~B}}, \overline{\mathrm{k}}_{1 \mathrm{C}}, \overline{\mathrm{k}}_{2 \mathrm{C}}, \overline{\mathrm{k}}_{3 \mathrm{C}}, \overline{\mathrm{k}}_{1 \mathrm{D}}, \overline{\mathrm{k}}_{2 \mathrm{D}}$, and $\overline{\mathrm{k}}_{3 \mathrm{D}}$ were calculated using the same method. As shown in Table $5, \overline{\mathrm{k}}_{1 \mathrm{~A}}$ is $1.62, \overline{\mathrm{k}}_{2 \mathrm{~A}}$ is 1.50 , and $\overline{\mathrm{k}}_{3 \mathrm{~A}}$ is $1.53 . \overline{\mathrm{k}}_{1 \mathrm{~B}}$ is 1.42 , $\overline{\mathrm{k}}_{2 \mathrm{~B}}$ is 1.61 , and $\overline{\mathrm{k}}_{3 \mathrm{~A}}$ is $1.61 . \overline{\mathrm{k}}_{3 \mathrm{C}}$ is $1.59, \mathrm{\textrm {k }}_{2 \mathrm{C}}$ is 1.64 , and $\overline{\mathrm{k}}_{3 \mathrm{C}}$ is $1.42 . \overline{\mathrm{k}}_{1 \mathrm{D}}$ is $1.30, \mathrm{k}_{2 \mathrm{D}}$ is 1.56 , and $\overline{\mathrm{k}}_{3 \mathrm{D}}$ is 1.79 .

For a certain factor, $\mathrm{R}$ is the difference value of $\mathrm{K}_{\text {imax }}$ and $\mathrm{K}_{i \min }$, namely the range. For example, $\overline{\mathrm{k}}_{1 \mathrm{~A}}$ is $1.62, \mathrm{k}_{2 \mathrm{~A}}$ is 1.50 , and $\overline{\mathrm{k}}_{3 \mathrm{~A}}$ is 1.53 . Thus, the $\mathrm{K}_{\text {imax }}$ and $\mathrm{K}_{\text {imin }}$ are 1.60 and 1.50, respectively, for the factor of $A$ (i.e., rainfall). And the value of $R_{A}$ is 0.12 . The value of $R_{B}, R_{C}$, and $R_{D}$ were calculated using the same method, and they were $0.19,0.22$, and 0.49 , respectively.

The larger the value of $\mathrm{R}$, the greater the influence of this factor on the safety factor in the orthogonal experiment. Thus, the order of influence on the safety factor of the landfill was as follows: compaction, drainage, slope, and rainfall. The compaction degree had the greatest impact on safety factor of slope, and the rainfall had the least impact on the safety factor slope. Miao (2019) believed that the influence of rainfall infiltration on the stability of a slope is not significant compared with the slope ratio, which agrees with the results of this paper [43].

\section{Conclusions}

In this study, the SWCC of MSW samples with different compaction densities from the Jiangcungou landfill in Xi'an was tested in the laboratory. In addition, information on the instability of 14 landfills was summarized and it was found that the primary causes of landfill instability included heavy rain, inadequate compaction, steep slopes, and failed leachate drainage systems. These factors that led to the instability of a landfill were discussed using the Jiangcungou landfill as an example. Based on the results, the following conclusions have been drawn:

The volumetric water content decreased with increasing matric suction. The SWCC of waste with different compaction degrees gradually converged with the increase in matric suction, when the matric suction was greater than $S_{2}$ in the shallow layer, greater than $M_{2}$ 
in the middle layer, and greater than $\mathrm{D}_{2}$ in the deep layer. Additionally, the SWCC of waste samples with different compaction degrees and the same components almost converged to a single point when the matric suction was about $10^{4} \mathrm{kPa}$. The volumetric water content of the converge point was less than 0.15 in the shallow layer, nearly 0.15 in the middle layer, and greater than 0.15 in the deep layer.

For waste with the same composition, the waste with a large compaction density tended to have a large $m$, a small $\alpha$, saturated water content $\theta_{s}$ saturated hydraulic conductivity $k_{\mathrm{s}}$ and $n_{v}$, and the little difference in residual water content, $\theta_{r}$. There was a modest trend of the friction angle and cohesion increasing with increasing compaction density. The relationship between the $\lg k_{s}$ and the dry density was a linear function. In addition, $\alpha$ value decreased fastest with the dry density when the waste was from the shallow layer and the slowest when the waste was from the deep layer.

Landfill instability was often caused by two or more factors. One adverse factor may not directly lead to landfill instability, but it may easily lead to instability when several adverse factors coexist. In the orthogonal test, the most dangerous working condition was with rainfall of $137.61 \mathrm{~mm}$ in three days, a slope ratio of $1: 3.5$, a failed drainage system, and low compaction; the minimum factor of safety was 1.19 . For the factors of compaction, the drainage system, the slope, and rainfall, the values of $\mathrm{R}$ (i.e. range) were $0.49,0.22$, 0.19 , and 0.12 , respectively, in the orthogonal test. Thus, the influences on safety factors of the landfill decreased in the following order: compaction $>$ the drainage system $>$ the slope $>$ rainfall. Hence, a good compaction can greatly reduce the probability of landfill instability. In operation management, the MSW should be compacted in strict accordance with the specifications.

\section{Acknowledgments}

The present study was supported by the Leadership Talent Project of Shaanxi Province High-Level Talents Special Support Program in Science and Technology Innovation (2017), the Natural Science Basic Research Program of Shannxi Province - Key Project (Program 2017JZ013), and the National Natural Science Foundation of China $(51679197,51922088)$.

\section{Conflict of Interest}

The authors declare no conflict of interest.

\section{References}

1. YANG R., XU Z.G., CHAI J.R. A review of characteristics of landfilled municipal solid waste in several countries: physical composition, unit weight, and permeability coefficient. Polish Journal of Environmental Studies, 27 (6), 2425, 2018.

2. KORAI M.S., ALI M., LEI C., MAHAR R.B., YUE D. Comparison of MSW management practices in pakistan and china. Journal of Material Cycles and Waste Management, 22 (2), 443, 2020.

3. YANG R., XU Z.G., CHAI J.R., QIN Y., LI Y.L. Permeability test and slope stability analysis of municipal solid waste in Jiangcungou Landfill, Shaanxi, China. Journal of the Air \& Waste Management Association, 66 (7), 655, 2016.

4. HUANG Y., FAN G. Engineering geological analysis of municipal solid waste landfill stability. Natural Hazards, 84 (1), 93, 2016

5. HE H.J., LAN J.W., CHEN Y.M., ZHENG L.H., SHI W. Monitoring and analysis of slope slip process at a landfill in Northwest China. Chinese Journal of Geotechnical Engineering, 37 (9), 1721, 2015 [In Chinese].

6. ATHANASOPOULOS G., VLACHAKIS V., ZEKKOS D., Spiliotopoulos G. The december $29^{\text {th }} 2010$ Xerolakka municipal solid waste landfill failure. Proceedings of the 18th International Conference on Soil Mechanics and Geotechnical Engineering, 309, 2013.

7. PENG R., HOU Y.J., ZHAN L.T., YAO Y.P. Back-analyses of landfill instability induced by high water level: case study of Shenzhen landfill. International Journal of Environmental Research and Public Health, 13 (1), 1, 2016.

8. BLIGHT G. Slope failures in municipal solid waste dumps and landfills: a review. Waste Management \& Research, 26 (5), 448, 2008.

9. STARK T.D., EID H.T., EVANS W.D., SHERRY P.E. Municipal solid waste slope failure. II: stability analyses. Journal of Geotechnical and Geoenvironmental Engineering, 126 (5), 408, 2000.

10. SEED R.B., MITCHELL J.K., SEED H.B. Kettleman Hills waste landfill slope failure. II: stability analyses. Journal of Geotechnical Engineering, 116 (4), 669, 1990.

11. ZOU D.H. Exploring a waste dump site failure-possible causes and prevention measures. International Journal of Geohazards and Environment, 2 (1), 25, 2016.

12. HOSSAIN S., HAQUE M.A. The effects of daily cover soils on shear strength of municipal solid waste in bioreactor landfills. Waste Management, 29 (5), 1568, 2009.

13. SHEN L. Liquid depth study and stability analysis of municipal solid waste landfill. M.D. thesis. Zhejiang University, Hangzhou, China, 2011 [In Chinese].

14. YU L., BATLLE F. A hybrid method for quasi-threedimensional slope stability analysis in a municipal solid waste landfill. Waste Management, 31, 2484, 2011.

15. QIU Z.H., HE C.M., ZHU B.J., CHEN H.L. Investigations of water transport in valley-type MSW landfills and their stabilities subjected to various rainfall patterns. Rock and Soil Mechanics, 33 (10), 3151, 2012 [In Chinese].

16. CHEN Y.M., LI J.C., YANG C.B., ZHU B., ZHAN L.T. Centrifuge modeling of MSW landfill failures induced by rising water levels. Canadian Geotechnical Journal, 54 (12), 1, 2017.

17. KOERNER R.M., SOONG T.Y. Leachate in landfills: the stability issues. Geotextiles and Geomembranes, 18, 293, 2000.

18. LI Y.L., SHE L., WEN L.F., ZHANG Q. Sensitivity analysis of drilling parameters in rock rotary drilling process based on orthogonal test method. Engineering Geology, 270, 105576 (1-9), 2020. 
19. WU X., LEUNG D.Y.C. Optimization of biodiesel production from camelina oil using orthogonal experiment. Applied Energy, 88, 3615, 2011.

20. FENG S.J., ZHENG Q.T., CHEN H.X. Unsaturated flow parameters of municipal solid waste. Waste Management, 63 (5), 107, 2017.

21. WU H.Y., WANG H.T., ZHAO Y., CHEN T., LU W.J.. Evolution of unsaturated hydraulic properties of municipal solid waste with landfill depth and age. Waste Management, 32 (3), 463, 2012.

22. DANG M.R., CHAI J.R., XU Z.G., QIN Y., CAO J., LIU F.Y. Soil water characteristic curve test and saturatedunsaturated seepage analysis in Jiangcungou municipal solid waste landfill, China. Engineering Geology, 264, 105374 (1-11), 2020.

23. VAN GENUCHTEN M.T. A closed-form equation for predicting the hydraulic conductivity of unsaturated soils. Soil Science Society of America Journal, 44 (5), 892, 1980.

24. MINISTRY OF HOUSING AND URBAN-RURAL DEVELOPMENT OF THE PEOPLE'S REPUBLIC OF CHINA. Technical specification for soil test of landfilled municipal soild waste. CJJ/T 204-2013, Beijing, China Construction Industry Press, 2013.

25. HE H.J., LAN J.W., CHEN Y.M., XIAO D.K., ZUO X.R., MA P.C. Monitoring and stability analysis of slope slip of a landfill with multiple intermediate covering layers. Journal of Southeast University (English Edition), 34, 104, 2018.

26. SHI W., CHAI X.L. Experiments on loess as intermediate cover in landfills in northwest China. Journal of Shanghai University (Natural science), 22 (4), 505, 2016 [In Chinese].

27. BREITMEYER R.J., BENSON C.H. Measurement of unsaturated hydraulic properties of municipal solid waste. Geo-frontiers, 2011, 1433, 2011.

28. JANG Y.S., KIM Y.W., LEE S.I. Hydraulic properties and leachate level analysis of Kimpo metropolitan landfill, Korea. Waste Management, 22 (3), 261, 2002.

29. REDDY K.R., HETTIARACHCHI H., PARAKALLA N., GANGATHULASI J., JEAN B., LAGIER T. Hydraulic Conductivity of MSW in Landfills. Journal of Environmental Engineering, 135 (8), 677, 2009.

30. JIE Y.X., XU W.J., DANZENG, D.Z., WEI Y.F., PENG T., ZHOU Z.Y. Laboratory testing of a densified municipal solid waste in Beijing. Journal of Central South University, 20, 1953, 2013.

31. CAO C., XU Z.G., CHAI J.R., LI Y.Q. Radial fluid flow regime in a single fracture under high hydraulic pressure during shear process. Journal of Hydrology, 579, 124142 (1-16), 2019.
32. KE H., HU J., XU X.B., WANG W.F., CHEN Y.M., ZHAN L.T. Evolution of saturated hydraulic conductivity with compression and degradation for municipal solid waste. Waste Management, 65, 63, 2017.

33. ZENG G., LIU L., XUE Q., WAN Y., MA J., ZHAO Y. Experimental study of the porosity and permeability of municipal solid waste. Environmental Progress \& Sustainable Energy, 36 (6), 1694, 2017.

34. GOMES C., LOPES M.L., OLIVEIRA P.J.V. Municipal solid waste shear strength parameters defined through laboratorial and in situ tests. Journal of the Air \& Waste Management Association, 63 (11), 1352, 2013.

35. LV X.L., ZHAI X.L., HUANG M.S., LAI H.B. Triaxial tests and analysis of shear strength of municipal solid waste at medium and high ages. Rock and Soil Mechanics, 36, 346, 2015 [In Chinese].

36. FENG S.J., GAO K.W., CHEN Y.X., Li Y., ZHANG L.M., CHEN H.X. Geotechnical properties of municipal solid waste at Laogang Landfill, China. Waste Management, 63, $354,2016$.

37. ZHAN L.T., CHEN Y.M., LING W.A. Shear strength characterization of municipal solid waste at the Suzhou landfill, China. Engineering Geology, 97, 97, 2008.

38. BRAY J.D., ZEKKOS D., JR E.K., ATHANASOPOULOS G.A., RIEMER M.F. Shear Strength of Municipal Solid Waste. Journal of Geotechnical and Geoenvironmental Engineering, 135 (6), 709, 2009.

39. BAREITHER C.A., BENSON C.H., EDIL T.B. Effects of Waste Composition and Decomposition on the Shear Strength of Municipal Solid Waste. Journal of Geotechnical and Geoenvironmental Engineering, 138 (10), 1161, 2012.

40. RAHIMI A., RAHARDJO H., LEONG E.C. Effect of antecedent rainfall patterns on rainfall-Induced slope failure. Journal of Geotechnical and Geoenvironmental Engineering, 137 (5), 483, 2011.

41. ZEKKOS D., ATHANASOPOULOS G.A., BRAY J.D., GRIZI A., THEODORATOS A. Large-scale direct shear testing of municipal solid waste. Waste Management, 30, 1544, 2010

42. MINISTRY OF HOUSING AND URBAN-RURAL DEVELOPMENT OF THE PEOPLE'S REPUBLIC OF CHINA. Technical code for geotechnical engineering of municipal solid waste sanitary landfill. CJJ176-2012, Beijing, China Construction Industry Press, 2012.

43. MIAO J.D. Investigation on geotechnical properties of stabilized MSWI fly ash and engineering applications. M.D. thesis, Zhejiang Science \& Technology University, Hangzhou, China, 2019 [In Chinese]. 